\title{
Supra- and Infratentorial Cystic Metastases of Breast Cancer: Case Report
}

\author{
Meme Kanserinin Supra- ve İnfratentorial Kistik Metastazları: Olgu Sunumu
}

\author{
Necati Tatarlı ${ }^{1}$, Yusuf Emrah Gergin ${ }^{1}$, Selçuk Özdoğan ${ }^{1}$, Bilgehan Solmaz $^{1}$, Mehmet Tiryaki ${ }^{1}$, \\ Dilek Yavuzer ${ }^{2}$, Tufan Hiçdönmez ${ }^{1}$
}

${ }^{1}$ Dr. Lütfi Kırdar Kartal Eğitim ve Araştırma Hastanesi, Nöroşirürji Kliniği, İstanbul

${ }^{2}$ Dr. Lütfi Kırdar Kartal Eğitim ve Araştırma Hastanesi, Patoloji Kliniği, İstanbul

Dergiye Ulaşma Tarihi:29/03/2015 Dergiye Kabul Tarihi:13/11/2015 Doi: 10.5505/aot.2016.87004

\section{ÖZET}

Meme kanserinin kranial metastazları; kemik, dura veya beyin parankimine olmaktadır. Semptomlar metastazın lokalizasyonuna göre değişir. Kitleler; solid, kistik veya parsiyel kistik şekilde olabilirler. Meme kanserinin kistik intrakranial metastazları oldukça nadirdir. Cerrahi sonrası radyoterapi ve/veya kemoterapi uygulanır. Kırksekiz yaşında bayan olgu, baş ağrısı ve generalize tonik-klonik nöbet şikayetleri ile başvurdu. Sekiz yıl önce sol meme kanseri nedeniyle sol total mastektomi ve sol koltukaltı lenfadenektomi ameliyatı yapılmış. Patolojisi adenoid kistik karsinom olarak gelmiş. Lenf nodlarında metastaz tespit edilen olguya adjuvan kemoterapi uygulanmış. Meme ameliyatından sekiz yıl sonra yapılan kranial MRG'sinde (Manyetik Rezonans Görüntüleme) sol frontalde ve serebellar orta hatta büyük kistik kitle lezyonları tespit edildi. Yapılan PET-CT (Pozitron Emisyon Tomografi) incelemesinde, başka herhangi bir organında metastaz tespit edilmedi. Meme açısından yapılan genel cerrahi konsültasyonunda herhangi bir patoloji bulunmadı. Her iki kranial lezyon nedeniyle bir hafta arayla iki kez ameliyat edilen olgunun yapılan patolojik incelemesinde, kistik meme kanseri metastazı tespit edildi. Ameliyat sonrasında olguya tüm beyin radyoterapi uygulandı. Kemoterapi uygulanmadı. Bu olgu dolayısıyla kranial kistik metastazlarda, ender de rastlansa meme kanseri metastazlarını ayırıcı tanıda düşünmemiz gerektiğini vurgulamak istedik.

Anahtar Kelimeler: Kistik intrakranial metastaz, meme kanseri, kistik metastaz, beyin metastazı

\begin{abstract}
Breast cancer is most frequently metastasize dura, bone and parenchyma in cranial tissue. Symptoms vary according to the location of the metastasis. Masses may be solid, cystic and partial cystic form. Cystic intracranial metastases of breast cancer is very rare. Radiotherapy and/or chemotherapy could be performed after surgery. Forty-eight-year-old female patient was admitted with complaints of headache and generalized tonicclonic seizure. Patient underwent surgery for cancer of the left breast for eight years ago. Left total mastectomy and left axillary lymphadenectomy was performed. Pathology was determined as adenoid cystic carcinoma. Adjuvant chemotherapy was applied to patients with lymph nodes metastasis detected. Cranial MRI (Magnetic Resonance Imagination) was performed after eight years after breast surgery. In the left frontal and cerebellar midline, large cystic mass lesions were detected in cranial MRI. PET-CT (Positron Emission Tomography) examination was not detected in any other organ metastases. There was no pathology in terms of breast surgery consultation. Both cranial lesions were underwent surgery twice in one week. In the pathological examination of the patient, cystic breast cancer metastasis was detected. Whole brain radiotherapy was performed to the patient after surgery. We want to emphasize that in cranial cystic metastasis, rarely come across if breast cancer metastasis should be considered in differential diagnosis.
\end{abstract}

Keywords: Cystic intracranial metastasis, breast cancer, cystic metastasis, brain metastasis

\section{Giriş}

Beyine metastaz yapan tümörler içinde akciğer kanserinden sonra ikinci sıklıkta meme kanseri görülür (1). Meme kanserinin kranial metastazlar1; kemik dura veya beyin parankimine olmaktadır. Bulgular, metastazın lokalizasyonuna göre değişir. Kitleler; solid, kistik veya parsiyel kistik şekilde olabilirler.
Meme kanserinin kistik intrakranial metastazları oldukça nadirdir(2). Başağrısı, başdönmesi, nöbet, bulant1, kusma gibi şikayetlerle başvururlar (3). Metastazın lokalizasyonuna göre hemiparezi, ataksi, afazi gibi bulgular oluşabilir (4). Teşhisten sonra tedavi, cerrahi olarak mümkün olduğunca kitleleri çıkarmaktır. Cerrahi sonrası radyoterapi ve/veya kemoterapi uygulanır. 


\section{Olgu Sunumu}

Kırksekiz yaşında bayan olgu, başağnısı ve generalize tonik-klonik nöbet şikâyetleri ile başvurdu. Sekiz yıl önce sol meme kanseri nedeniyle sol mastektomi ve sol koltukaltı lenfadenektomi ameliyatı yapılmış. Patolojisi adenoid kistik karsinom olarak gelmiş. Lenf nodlarında metastaz tespit edilen olguya adjuvan kemoterapi uygulanmış.

Meme ameliyatından sekiz y1l sonra yapılan kranial MRG'sinde (Manyetik Rezonans Görüntülemesi), sol frontalde ve serebellar orta hatta büyük kistik kitle lezyonlar1 tespit edildi (Resim 1,2,3). YapilanPET-CT (Pozitron Emisyon Tomografi) incelemesinde, başka herhangi bir organında metastaz tespit edilmedi. Meme açısından yapılan genel cerrahi konsültasyonunda herhangi bir patoloji bulunmadi. Meme kanseri teşhisinden sekiz yil sonra oluşan iki kranial lezyon için, olgu 1 hafta arayla iki kez ameliyat edildi. Olgunun yapilan patolojik incelemesinde; 3-4 mm kesitler ile $\mathrm{H}+\mathrm{E}$ (Hematoksilen + Eozin) boyama yapıldı ve 1şık mikroskopu ile bakıldı. Nöroglial dokuyu infiltre eden epitelyal tümör gözlendi. Dokuya; CK (cytokeratinsitokeratin), GCDFP-15 (Gross Cystic Disease Fluid Protein-15), Mamoglobin ve Östrojen Reseptörü uygulandı ve hepsi pozitif olarak geldi. Progesteron ve HER-2 (Human Epidermal Growth Factor Receptor-2) reseptörleri ile boyanma tespit edilmedi. Olgunun patolojisi, meme kanseri metastazi olarak değerlendirildi (Resim 4,5,6,7). Ameliyat esnasinda ve sonrasinda herhangi bir komplikasyon gelişmeyen olguya,daha sonraki dönemde tüm beyin radyoterapi uygulandı. Kemoterapi uygulanmadi.

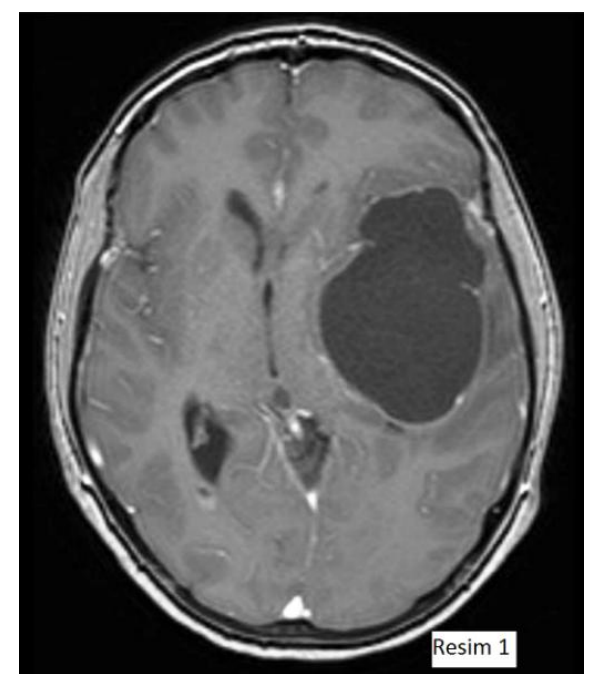

Resim 1: Kranial T1 ağırlıklı kontrastlı aksial MRG (Manyetik Rezonans Görüntüleme) kesitinde çevresel ödemi bulunan sol temporal kistik lezyon görülmekte.

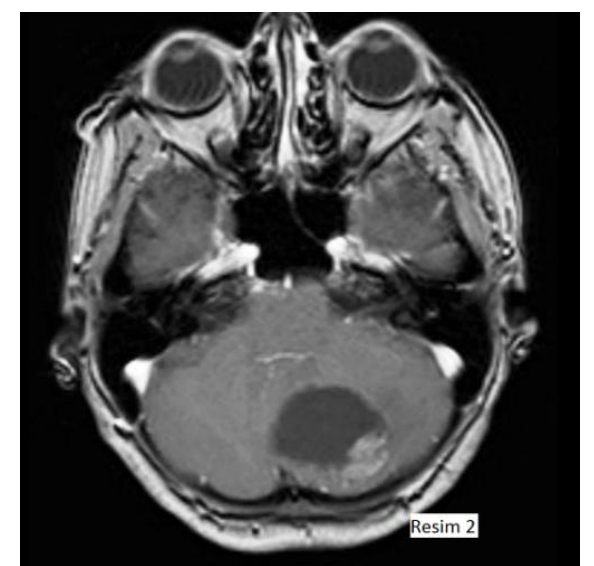

Resim 2: Kranial T1 ağırlıklı kontrastlı aksial MRG kesitinde serebellar kistik lezyon izlenmekte.

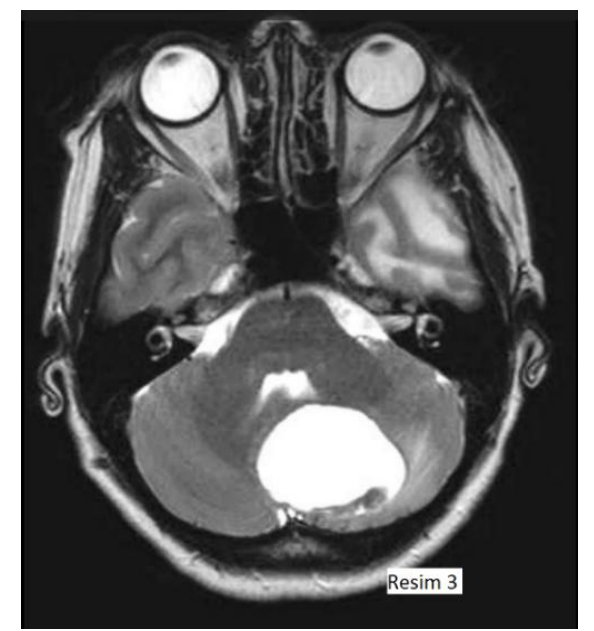

Resim 3:Kranial T2 ağırlıklı aksial MRG kesitinde hafif çevresel ödemi bulunan serebellar kistik lezyon görülmekte. 


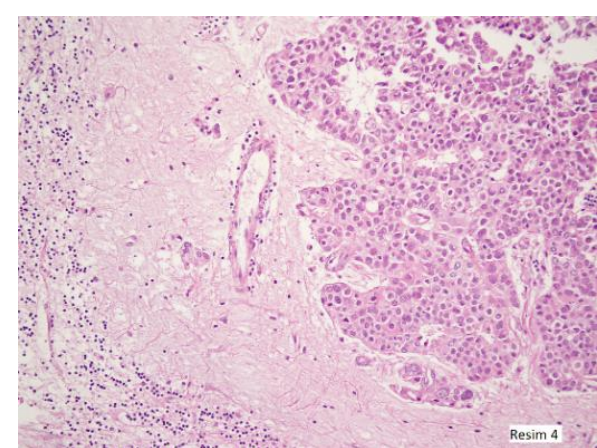

Resim 4: H+E (Hematoksilen + Eosin) ile boyanan ve nöroglial dokuyu infiltre eden epitelyal tümör gözlenmekte (X200, H+E).

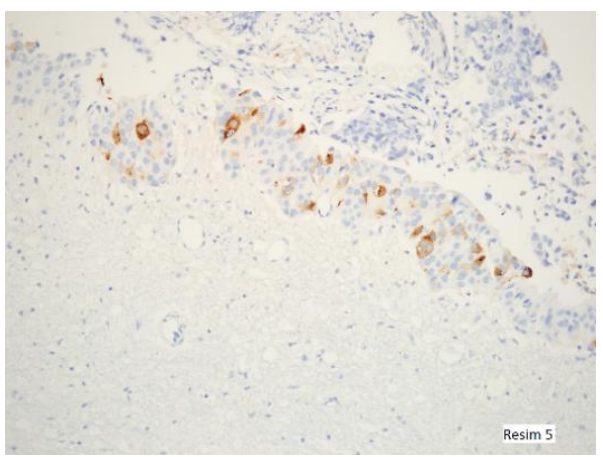

Resim 5: GCDFP-15 (Gross Cystic Disease Fluid Protein-15) ile pozitif boyanan tümör hücreleri izlenmekte (X200, GCDFP-15).

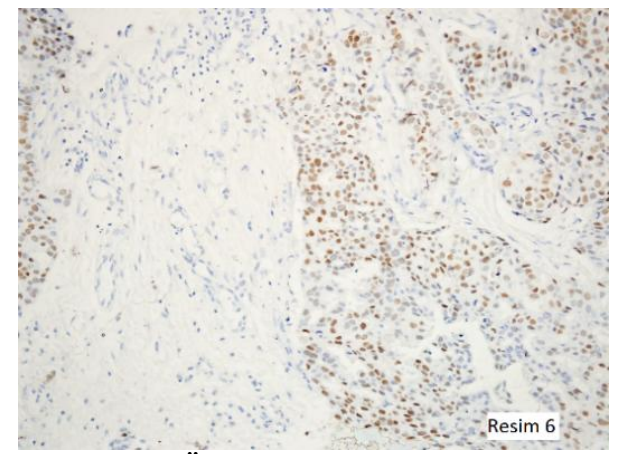

Resim 6: Östrojen ile pozitif boyanan epitelyal tümör hücreleri görülmekte (X200, +Östrojen).

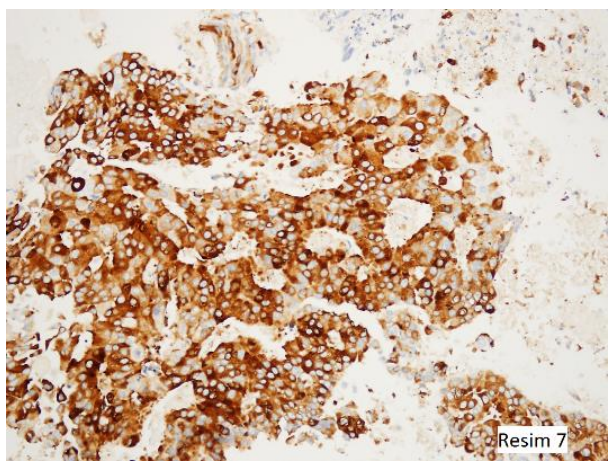

Resim 7: Mammoglobin ile pozitif boyanan tümör hücreleri izlenmekte (X200, Mammoglobin).

\section{Tartışma}

Yapılan bir çalışmada meme kanserli 650 olgunun otopsisinde, 36 olguda intrakranial metastaz tespit edilmiştir(1).Sistemik kanseri olan olguların (akciğer, meme, gastrointestinal sistem, melanom, ürogenital sistem, tiroid) \%20-25'inde intrakranial metastaz oluşma olasılığ1 vardır $(2,3,4)$. Beyin metastazlarının \%20-30'u serebellar metastaz olarak görülür (2). Erişkinde serebellar kitlelerin çoğunluğu metastazdır. Serebellar metastazların \%44'ü tek lezyon iken, \%56's1 ise birden çok lezyon barındırır. \%64 olguda başağrısı, yürüme bozukluğu, bulantı, kusma veya başdönmesi gibi semptomlar mevcuttur $(2,3,4)$.

Akciğer kanserinden sonra en sik intrakranial metastaz yapan kanser, meme kanseridir ve tüm metastazların \% 20'sidir (5). Meme kanseri genellikle solid kitle tarzında metastaz yapar (6). Meme kanserinin serebellar kistik metastazı literatürde oldukça nadirdir (7).

Meme kanserinde adjuvan terapiler ile primer hastalığın kontrolünün iyi yapılması sonucunda, rölatif olarak kemorezistan olan intrakranial metastaz insidansı artmaktadır. Ortalama sağkalım yaklaşık 12 ay, bir yıllık sağkalım oranı ise \%57'dir (1).

Leavens ve ark., MD Anderson Kanser Merkezi'nde soliter metastazektomi ile beraber radyoterapi uygulanmış 33 olgu üzerindeki çalışmalarını yayınlamışlardır (6). Ortalama sağ kalım 15 aydır. Olguların tümü solid metastazlardir.

Pieperve ark., 1983-1992 y1lları arasında tedavi edilmiş 63 olguluk bir seride; cerrahi ile beraber radyoterapi uygulanmış bu olgularda ortalama sağ kalımı 16ay, beş yıllık sağkalım oranını ise \%17olarak bildirmişlerdir (8). Sağ kalımın uzun olmasının faktörlerini ise; yaş, menopozal durum, postop radyoterapi görmeleri, preop iyi nörolojik tabloya sahip olmaları ve sistemik hastalığın kontrol altında olması olarak sıralamışlardır. Olguların hiçbirinde kistik metastaz yoktur.

De Ieso ve ark., HER-2 pozitif olan olgularda, HER-2 negatif olan olgulara göre ortanca sağkalım daha yüksek olup, daha agresif lokal tedavi uygulanması gerektiğini vurgulamışlardır (9). Leone ve ark., meme kanserinin teşhis anındaki evresi yüksek oldukça, teşhis ile beyin metastazı gelişmesi arasındaki sürenin o kadar kısa olduğunu göstermişlerdir (10). Nishimura ve ark., beyin 
metastazı gelişen meme kanseri olgularının opere edildikten ve ard1 sira tüm beyin radyoterapisi aldıktan sonra, olgulara sistemik kapesitabin ve trastuzumab ile kemoterapi uygulanmasının ortanca sağkalımı anlamlı şekilde uzattığını bildirmişlerdir (11).

$\mathrm{Bu}$ olgu dolayısıyla kranial kistik metastazlarda, ender de rastlansa meme kanseri metastazlarını ayırıcı tanıda düşünmemiz gerektiğini vurgulamak istedik.

\section{Çıkar Çatışması: Yok}

\section{Referanslar}

1. Ahmad A, Hart IR. Mechanisms of metastasis. Crit Rev Oncol Hematol. 1997;26(3):163-73

2. Bentson JR, Steckel RJ, Kagan AR. Diagnostic imaging in clinical cancer management: brain metastases. Invest Radiol.1988;23(5):335-41

3. Dela Monte SM, Hutchins GM, Moore GW. Influence of age on the metastatic behavior of breast carcinoma. Hum Pathol. 1988;19(5):529-34

4. Fadul C, Misulis KE, Wiley RG. Cerebellar metastases: diagnostic and management considerations. J Clin Oncol. 1987;5(7);1107-15

5. Galicich JH, Arbit E, Wronski M: Metastatic brain tumors. In: Wilkins RH, Rengachary SS, eds. Neurosurgery (vol 1,2nd ed). New York; McGrawHill;1996:807-21

6. Leavens ME, Moser RP, Obbens EAMT, Iwata, KI. Surgical treatment of metastatic brain tumors. The Cancer Bullatin 1986;38:38:9

7. Stadnik T, Deroover J, Gosens A, Michotte A, Freson M, Osteaux M. Calcified, cystic brain metastases. Eur J Radiol. 1997;25(1):36-40

8. Pieper D, Hess KR, Sawaya RA. The role of surgery in the treatment of brain metastases in breast cancer patients (abstract). Society of Surgical Oncology Fourth Annual Cancer Symposium, 1996, p 31

9. De Ieso PB, Schick U, Rosenfelder N, Mohammed K, Ross GM. Breast cancer brain metastases - A 12 year review of treatment outcomes. Breast. 2015;24(4):426-33

10. Leone JP, Lee AV, Brufsky AM. Prognostic factors and survival of patients with brain metastasis from breast cancer who underwent craniotomy. Cancer Med. 2015. [Epub ahead of print]

11. Nishimura A, Nishi T, Morohashi S, Okano K, Hakamada K. The case of a long-surviving patient with breast cancer and brain metastases treated using multidisciplinary therapy. Gan To Kagaku Ryoho. 2014;41(12):1897-9 